The Barrios Altos Recovery

Project: Towards a participatory approach of urban renewal
PALABRAS CLAVE | PARTICIPACIÓN COMUNITARIA | PARTICIPACIÓN CIUDADANA | RENOVACIÓN URBANA PARTICIPACION CIUDADAS HISTORICOS

KEYWORDS | COMMUNITY PARTICIPATION I CITIZEN PEYWORDS F COMMUNITY PARTICIPATION I CITIZEN

\section{| RESUMEN |}

El sector de Barrios Altos, en el Centro Histórico de Lima, ha sido en los últimos años objeto de diversas iniciativas de renovación urbana que han quedado inconclusas. La última de ellas fue el Programa de Mejora de las Condiciones de Habitabilidad de Barrios Altos, en el año 2014.

El artículo asume este caso demostrativo para analizar el rol de la participación de la comunidad como un componente clave en el proceso de transformación de la ciudad, en el marco de una revisión y reflexión teórica sobre gestión participativa. De esta manera, se esboza una propuesta conceptual sobre renovación urbana participativa.

\section{| ABSTRACT |}

In recent years, the Barrios Altos neighborhood, in the Historic Center of Lima, has been a target of various urban renewal initiatives that have remained unfinished. The last one was the "Program for the unfinished. The las mprovement of Habitability Conditions in Barrios Altos" in 2014.

The article takes this demonstrative case to analyze the role of community participation as a key component in the process of city transformation using the framework of a theoretical review and reflection on participatory management. Thus, a conceptual proposal of participatory urban renewal can be outlined.

\title{
El Programa de Recuperación de Barrios Altos: hacia un enfoque participativo de la renovación urbana
}

\author{
MAURO JURADO SALCEDO*·Lima, Perú·mjurado@pucp.pe \\ Fecha de recepción: 31 julio 2016 · Fecha de aceptación: 27 septiembre 2016
}

\section{INTRODUCCIÓN}

La ciudad de Lima en su mayor parte ha sido producto de la autoconstrucción: según la Cámara Peruana de la Construcción, anualmente se construyen 30 mil viviendas informales (Sandoval, 2016), sin licencia o sin mediar intervención profesional. Con respecto al diseño urbano, el panorama es similar.

En este contexto, el Centro Histórico de Lima cobra una especial relevancia, al ser una porción de la ciudad que sí respondió a una planificación ${ }^{1]}$. Sin embargo, la evolución, densificación y transformación de la ciudad, ha puesto en duda la vigencia del centro histórico como un sitio para habitar, advirtiendo la necesidad de su renovación urbana.

Barrios Altos, forma parte del Centro Histórico de Lima (FIGURA 1), y fue nombrado de esta manera al localizarse en la parte alta de la Lima Virreinal (Shimabukuro, 2015). Formado por una trama urbana irregular, que obedece a la cuadrícula del Damero de Pizarro y a un antiguo trazado agrícola. En esta zona solían vivir esclavos e indígenas, apartados del centro de la ciudad.

Este barrio fue construido utilizando predominantemente un modelo de quinta, llamado también callejón, que cumplía la función de generar accesibilidad hacia el interior de las enormes manzanas.

En la actualidad, Barrios Altos se ha convertido en una de las realidades urbanas más complejas y con mayor concentración de problemas: el desabastecimiento de servicios básicos, la falta de espacios y equipamientos públicos, el estado de vulnerabilidad física de las viviendas, la insalubridad, la tugurización, el estado de deterioro de monumentos históricos, los conflictos de tenencia legal de los lotes, y sobre todo, la falta de iniciativas para la mejora de la calidad urbana y habitabilidad en este sector, que respondan a las necesidades y aspiraciones de sus habitantes (FIGURA 2).

* Arquitecto de la Pontificia Universidad Católica del Perú. Se tituló con la tesis "Vivienda colectiva y feria comercial con fines de renovación urbana en el Rímac". Ha realizado estudios de especialización en formulación de proyectos de inversión pública y en planificación territorial. Ha trabajado en EMILIMA (2014), como parte del equipo de diagnóstico social del Programa de Mejora de las Condiciones de Habitabilidad de Barrios Altos, en el Servicio de Asistencia Técnica Legal para la Renovación Urbana de la Municipalidad Metropolitana de Lima, Perú (2014) y en la Oficina de Proyectos Especiales No Viales (OPEN) de la Municipalidad Metropolitana de Lima. Perú (2015).

[1] La cuadrícula de Lima fue diseñada por Francisco Pizarro en 1535 y superpuesta en el trazo de la Lima prehispánica. A este diseño se le conoce como Damero de Pizarro (Hamann, 2011). 
Entre las iniciativas de intervención en Barrios Altos, realizadas por entidades públicas e instituciones privadas, se encuentran numerosos estudios y diagnósticos que han buscado recoger la problemática social y urbana ${ }^{[2]}$.

Otro tipo de intervenciones han sido los llamados concursos de ideas, realizados por el Programa Patrimonio para el Desarrollo de la Cooperación Española. El primero de ellos fue convocado para la renovación de cinco inmuebles del Centro Histórico de Lima (2010), cuatro de los cuales se encontraban ubicados en Barrios Altos, y el segundo para la rehabilitación de cinco espacios públicos en el eje de Jr. Ancash (2011), también en Barrios Altos. Estos eventos, al tener importante acogida, permitieron generar interés en el sector académico sobre la problemática de Barrios Altos y empezar una discusión propositiva desde el ámbito de la arquitectura.
1. Ubicación de la zona de Barrios Altos (en amarillo) en el contexto del Centro Histórico de Lima. Mapa del Centro Histórico de Lima - Barrios Altos, Aarón Herencia.

2. Problemática de deterioro de los inmuebles y desabastecimiento de servicios básicos. Fotografías de Barrios Altos, archivo personal del autor.


[2] La consultoría a cargo de Vargas (2014) y el estudio socioeconómico de Barrios Altos a cargo de Alegre (2014). 
A nivel de planes y proyectos preliminares se formularon en el año 2014, el Plan Específico de Barrios Altos, a cargo de la Gerencia de Desarrollo Urbano de la Municipalidad de Lima, que contemplaba un plan de zonificación, un conjunto de proyectos viales y la identificación de zonas destinadas a habilitación urbana y reurbanización y el Programa de Mejora de las Condiciones de Habitabilidad en el Centro Histórico de Lima - Barrios Altos ${ }^{[3]}$, a cargo de la Empresa Municipal Inmobiliaria de Lima, que contemplaba una propuesta de mejora de la infraestructura pública, intervención de fachadas de inmuebles de valor patrimonial y la creación de un complejo deportivo cultural.

Ambas iniciativas llevaron a cabo procesos de recojo de información y crearon expectativas en la población, sin embargo, no tuvieron éxito y se detuvieron en su fase de formulación (etapa de preinversión).

Ante este problema surgen una serie de preguntas: ¿̇Por qué los procesos de renovación urbana iniciados en Barrios Altos no se lograron concretar? ¿̇Los mecanismos de gestión utilizados guardan alguna relación con estos procesos inconclusos? ¿Qué enfoques y estrategias de participación se han utilizado en dichos procesos?

Utilizando el caso del Programa de Mejora de las Condiciones de Habitabilidad en el Centro Histórico de Lima - Barrios Altos ${ }^{[4]}$ (en adelante Programa de Recuperación de Barrios Altos) se busca dar respuesta a estas interrogantes.

Más allá de las explicaciones correspondientes a la viabilidad económica y el financiamiento, que han condicionado algunos procesos, la experiencia muestra algunas barreras en relación a la manera como se ha gestionado la participación de la comunidad, factor clave para la viabilidad social del proyecto arquitectónico y urbano en el marco de la renovación urbana.

\section{MARCO CONCEPTUAL}

\section{PERSPECTIVAS DE RENOVACIÓN URBANA}

El concepto de renovación urbana ha evolucionado desde su origen. En 1950 para el economista Miles Calean, este era un proceso de reestructuración y reordenamiento de una ciudad que ha perdido vigencia en sus usos con el tiempo o que ha sufrido deterioro.

En las décadas de los setentas y los ochentas, el concepto fue entendido de manera más radical, llegando a significar la destrucción y sustitución de sectores de ciudad por un nuevo tejido e infraestructura urbanos (Vives, 2013). La actuación de la población no estaba muy definida en ese momento.

En algunos casos la comunidad tenía un papel pasivo, al ser receptora de los nuevos servicios implementados con la transformación de la ciudad. En otros casos, la comunidad llegaba a ser vulnerada, al ser parte de procesos que la desplazaban de su lugar de origen para dar lugar a nuevos usos y nuevas estructuras sociales y urbanas.

En la experiencia latinoamericana los procesos de renovación urbana han traído consigo un fenómeno de gentrificación, en donde los viejos habitantes no son capaces de sostener el nuevo coste de la ciudad transformada y naturalmente se movilizan hacia otras zonas (Hernández, 2013). Esto a su vez fomenta mayor inversión privada en las áreas intervenidas.
En la actualidad en los países en vías de desarrollo, se entiende la renovación urbana como un proceso que involucra de manera activa y participativa a sus habitantes, centrándose más en su calidad de vida, que en la calidad de las edificaciones y espacios físicos de la ciudad.

Para que estos procesos sean realmente participativos y democráticos, existen ciertas condiciones: que la población confíe en el Estado, que exista equidad en la sociedad, que la sociedad esté organizada con representantes y que existan los mecanismos para que estos representantes funjan como interlocutores con el Estado (Estremadoyro, Uceda, Obregón y O'Phelan, 2010).

Según Hernández (2013), la renovación urbana como concepto es el proceso más complejo de transformación de la ciudad, diferenciándose de otros procesos de menor complejidad como recuperación, rehabilitación o restauración, en el que confluyen aspectos económicos, arquitectónicos, culturales, sociales, entre otros.

Es posible sintetizar la renovación urbana en los siguientes componentes físicos:

1. Espacio público: refacción, mejoramiento o creación de parques, plazas, calles, paseos, vías, etcétera.

2. Equipamiento público: implementación, mejoramiento o transformación de edificaciones de servicios de salud, educativos, culturales, recreativos, etcétera.

3. Infraestructura urbana: mejoramiento o provisión de servicios básicos como alumbrado, luz, agua, desagüe, etcétera.

4. Vivienda: mejoramiento, creación o saneamiento de espacios de habitación dignos y saludables.

Existe además un quinto componente: la participación, entendido como procesos de consulta, concertación con actores y representación de la sociedad en la toma de decisiones, mediante la cual se llevan a cabo los procesos de transformación (FIGURA 3).
[3] Este programa toma este título en su fase de formulación. Posteriormente en la etapa de diagnóstico social,
a través de una propuesta comunicacional, se le titula Programa Recuperemos Barrios Altos (Salcedo, 2014)
Este programa tiene dos fases, una primera de formulación de perfil de preinversión (EMILIMA, 2014) y una
segunda de diagnóstico social (Salcedo, 2014). 
3. Diagrama que clasifica los distintos tipos de intervenciones urbanas en cuatro componentes con un quinto componente central de participación comunitaria. Componentes de la renovación urbana, elaboración propia.
4. Diagrama que reconstruye a partir de las teorías de Arnstein (1969) y Bronfman y Gleizer (1994) tres niveles crecientes de participación. Niveles de participación, elaboración propia.
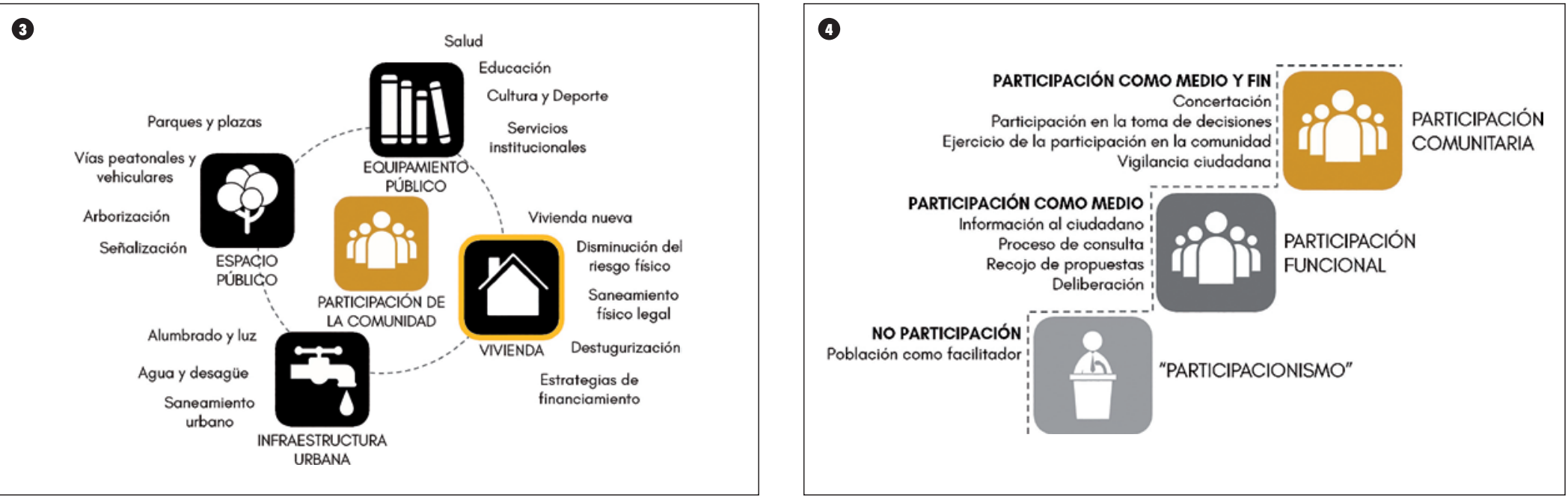

En esta clasificación de componentes, la vivienda tiene un lugar prioritario ${ }^{[5]}$. La vivienda digna y saludable es el objetivo principal de la renovación urbana, en el cual convergen los aspectos físicos, sociales, legales y económicos de los procesos de transformación de la ciudad (Estremadoyro et al., 2010).

\section{LA PARTICIPACIÓN, ¿̇MEDIO O FIN?}

La participación, entendida desde un enfoque de ciudadanía, es un proceso mediante el cual la población interviene en la organización de la sociedad, y en los cambios que se puedan generar en esta, por medio de la toma de decisiones (Estremadoyro et al., 2010).

Si la ciudadanía está organizada, la participación se canaliza mejor a través de los actores sociales, que son los sujetos colectivos estructurados a partir de una conciencia de identidad propia, portadores de valores y que poseen un cierto número de recursos que le permiten defender sus intereses (UBA, 2013).
Los actores sociales deben ser consultados en tanto fuerzas sociales y como mediadores representativos de la población e instituciones (Matus, 1987). No deben ser obviados, pues representan diferentes visiones de mundo y configuraciones que responden a la dinámica del propio territorio: sus tensiones, negociaciones y consensos (Cañizares, 2013).

Diversos autores han reconocido la necesidad de diferenciar niveles o grados de participación. Entre ellos Arnstein, quien en 1969 formuló una escalera de participación, en la que definía la no participación, entendida como manipulación, la participación simbólica y el poder ciudadano, que implica la coparticipación, delegación de poder y control ciudadano (Guillen, Saenz, Badii y Castillo, 2009).

La participación también puede ser entendida como medio o como fin. Existe una concepción de participación subordinada a las iniciativas e intervenciones planteadas por los técnicos burócratas (Palma, 2000). A esta participación la llama funcional, pues sirve como mecanismo de viabilidad social, es decir, actúa como un medio instrumental.

Bronfman y Gleizer (1994) debaten acerca del concepto de participación comunitaria y lo entienden como un proceso en el cual el involucramiento de la población no termina en la implementación del proyecto o la políitica, sino que busca el desarrollo y la autosuficiencia de la comunidad. En este concepto, la participación se entiende como un fin en sí mismo.

Según estos conceptos, se pueden definir tres niveles de participación (FIGURA 4):

1. Participación comunitaria: los actores de una sociedad tienen la capacidad y autonomía para resolver de manera efectiva los problemas de su comunidad, más allá de un proyecto o intervención específica (participación como medio y como fin).

2. Participación funcional: la participación se utiliza solo como medio para la validación de una intervención o política concreta.

[5] Experiencias diversas de renovación urbana como las llevadas en Los Guido de Desamparados en Costa Rica (Vidal Gómez, 2014), en Villa Libertador, en Córdova, Argentina (Maffrand y Martínez Rusconi, 2001), en el caso del Plan Parcial Fenicia en Bogotá, Colombia (Caicedo, 2013), o en otras localidades de Latinoamérica ponen como prioridad de los procesos de transformación la mejora de la habitabilidad a través del mejoramiento o creación de vivienda. 
3. Participacionismo ${ }^{[6]}$ : los elementos de la participación a nivel del discurso, esconden intereses adversos a los de un proceso realmente participativo y democrático.

El concepto de participación comunitaria va de la mano con el concepto de desarrollo humano, en el cual se busca que los sistemas de organización social sirvan al desarrollo de las potencialidades y libertades de las personas, y no que las personas sirvan a los sistemas de organización social (Espejo, 2009).

La participación como expresión de libertad del ser humano, debe servirse de los medios para llegar a todo su potencial, y estos medios pueden ser los procesos de transformación y restructuración de la sociedad, por ejemplo: la renovación urbana.

\section{EL CASO DE BARRIOS ALTOS}

\section{EL PROGRAMA DE RECUPERACIÓN DE BARRIOS ALTOS Y SUS COMPONENTES}

El contexto en el que se sitúa Barrios Altos resulta especialmente complejo para la implementación de un proceso de renovación urbana con un enfoque participativo, pues se trata de un sector del Centro Histórico de Lima.

La renovación de los centros históricos generalmente toma como punto central el patrimonio histórico y la herencia pasada, para sustentar una transformación urbana, a modo de mantener vigencia y relevancia en estos sectores dentro del tejido urbano (Vives, 2013). Es así que los habitantes actuales de los centros históricos suelen pasar a segundo plano, en la búsqueda de la preservación de lo construido.

[6] Este término es comúnmente usado para referirse a un mecanismo no participativo, pero que aparenta serlo, que en el fondo busca legitimar las decisiones tomadas por las esferas de poder, como lo señala De la Cruz (2016).

5. Ubicación de la zona de intervención del programa (en amarillo) en el contexto de Barrios Altos (en azul). Mapa de Programa de Recuperación de Barrios Altos, Aarón Herencia.

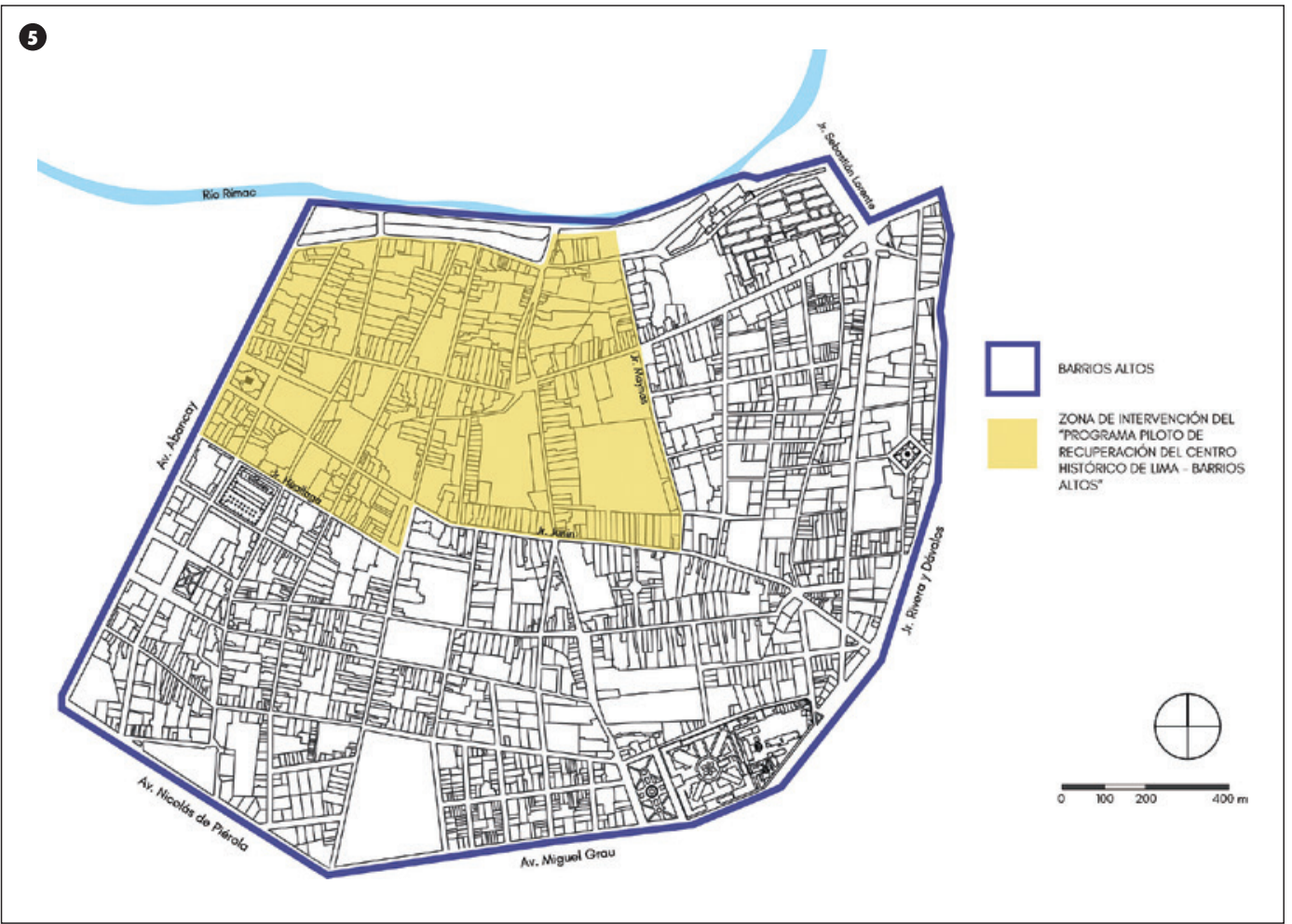

El Centro Histórico de Lima, es además Patrimonio Cultural de la Humanidad, declarado por la UNESCO en 1988 (FIGURA 1), lo cual hace intangible su tejido urbano, complejizando los procesos estructurales de renovación.

Es en este contexto, que la Municipalidad Metropolitana de Lima llevó a cabo de numerosas iniciativas inconclusas de proyectos de rehabilitación y renovación urbana en Barrios Altos. La última intervención tuvo lugar en el año 2014 con el Programa de Recuperación de Barrios Altos, a cargo de la Empresa Municipal Inmobiliaria de Lima. Este programa propuso la implementación de un conjunto de medidas a nivel espacio público, infraestructura urbana y equipamiento, comprendiendo 69 hectáreas del sector de Barrios Altos, las cuales albergan a aproximadamente 13 mil habitantes (EMILIMA, 2014) (FIGURA 5).

Esta zona fue escogida por su ubicación estratégica en el Centro Histórico de Lima y por presentar características diversas y representativas dentro de los límites del cuadrante (existían en la zona elegida lotes de uso comercial, residencial y mixto). Esta cualidad, según EMILIMA, lo hacía un programa replicable en otros contextos aledaños (2014).

El programa tuvo como objetivo la mejora de las condiciones de habitabilidad del barrio, para ello planteó cinco proyectos de inversión distintos (EMILIMA, 2014):

- Proyecto 1. Mejoramiento y rehabilitación de vías urbanas y fachadas monumentales. Este proyecto incluía la dotación de señalización, tachos, bancas, refacción de pistas y veredas. Asimismo, la recuperación de las fachadas de los inmuebles con valor histórico monumental.

- Proyecto 2. Mejoramiento del sistema de agua y desagüe de las redes públicas.

- Proyecto 3. Construcción de un sistema de galerías subterráneas para albergar servicios 
públicos como luz, agua, desagüe, fibra óptica, gas y conexiones de uso doméstico.

- Proyecto 4. Mejoramiento de las capacidades institucionales de la Municipalidad Metropolitana de Lima para atender temas de desarrollo urbano.

- Proyecto 5. Construcción de un equipamiento urbano de carácter recreativo deportivo.

El proceso de formulación del programa se inició con la revisión documental y diagnóstico preliminar a partir de los numerosos estudios que se habían realizado con anterioridad en la zona:

- El Banco Interamericano de Desarrollo había trabajado en una caracterización de la problemática urbana de Barrios Altos, con el objetivo de formular estrategias financieras y legales para la generación de suelo urbano, con miras a posibles proyectos de renovación urbana (Vargas, 2014).

- PNUD (Programa de las Naciones Unidas para el Desarrollo), en conjunto con el Instituto de Defensa Civil, había trabajado en la elaboración de un mapa de riesgos físicos en caso de siniestros (EMILIMA, 2014).

- La ONG ELIS (Eficiencia Legal para la Inclusión Social) había realizado un estudio socioeconómico en los hogares de Barrios Altos (Alegre, 2014).

Se recogieron evidencias observables de un conjunto de problemas, como el exceso de tráfico vehicular debido a las constantes reparaciones en las pistas, la delincuencia expresada por vecinos y visitantes, así como la falta de espacios de esparcimiento, acentuada por la presencia constante de niños, provenientes de los numerosos colegios de la zona (EMILIMA, 2014).

Cuando los proyectos ya habían sido planteados por un equipo técnico en la fase de preinversión, se convocó a un proceso de diagnóstico social para validar la pertinencia de las intervenciones propuestas.
Es en este momento que se pone en marcha una investigación de carácter participativo y se recogen posturas diversas y contrapuestas sobre algunos componentes de la intervención, además de posturas y percepciones de los vecinos sobre sus propias necesidades y demandas. Una de estas, percibida como prioritaria por la mayor parte de vecinos, fue el mejoramiento de las viviendas (Salcedo, 2014). Sin embargo, el programa limitó la intervención en vivienda al mejoramiento de las fachadas de ciertos inmuebles considerados por el Ministerio de Cultura como de valor histórico monumental (EMLIMA, 2014).

El enfoque real del programa estaba orientado hacia el mejoramiento de las calles, en donde las viviendas formaban parte del conjunto urbano del Centro Histórico de Lima, no obstante, son referenciadas como elementos de ornamentación y no como parte integral de la propuesta.

Como señala Vargas (2014), la situación de entrampamiento legal en la que se encontraban los solares de Barrios Altos, dificultaba las iniciativas de intervención. Se encontraron situaciones de ausentismo de los propietarios, ventas de inmuebles no regularizadas, subdivisión de lotes como parte de procesos de herencia, entre otros. Del mismo modo, se identificó que la tipología predominante de vivienda eran las quintas, espacios en los que 20 a 50 familias comparten servicios básicos, entre otras características. Todo ello advertía de la complejidad de un proceso poco viable para el mejoramiento y creación de viviendas en conjunto con la inversión privada.

En materia de equipamiento público, se planteó la implementación de un complejo deportivo en la zona, el cual respondía a la demanda de niños y ióvenes que provenían de los colegios del lugar. Este equipamiento buscó además de manera indirecta la prevención de situaciones de alto riesgo, como el uso de drogas y la delincuencia que atacan a grupos vulnerables de niños y jóvenes, que no tienen alternativas de esparcimiento.
La implementación de losas deportivas o skateparks como los planteados por el programa (EMILIMA, 2014), son una alternativa de fácil autogestión. No implican la provisión de un servicio permanente provisto por el Estado y son de bajo coste. Según Lira (2016), la acción del Estado muchas veces se limita a este tipo de infraestructura básica, sin tomar en cuenta servicios de calidad para los ciudadanos.

El resto de intervenciones planteadas por el programa contemplaba la problemática originada por las constantes reparaciones menores que se realizan en las pistas, veredas y en los sistemas de agua y desagüe de las vías públicas, que se encontraban en un estado de deterioro o de colapso debido a su antigüedad y mal uso. Por ello la propuesta incluía la construcción de galerías subterráneas de servicios, más un nuevo sistema de redes de agua y desagüe, además de una posterior reparación de las pistas y veredas en el nivel superior (EMILIMA, 2014).

El problema de abastecimiento de servicios básicos, en su mayoría se encontraba en la red privada, la cual no fue parte de la intervención del programa. Este componente observaba entonces un alcance limitado en relación a la solución de la problemática detectada.

En resumen, el Programa de Recuperación de Barrios Altos abordó un conjunto de componentes (FIGURA 6), que buscaban atacar problemas adecuadamente diagnosticados, pero de una manera limitada y desarticulada, sin una visión de ciudad que involucre a los ciudadanos de una manera activa, ni a todas las entidades e instituciones que debieran ser parte de un proceso de renovación urbana. El diagnóstico social realizado por Salcedo (2014), evidenció una distancia entre las expectativas de los vecinos de Barrios Altos y los proyectos planteados por EMILIMA y una percepción general de que los problemas más urgentes no estaban siendo atendidos. 
6. Diagrama de ubicación de las intervenciones del Programa de Recuperación de Barrios Altos clasificadas en cuatro componentes. Componentes de renovación urbana del programa, Aarón Herencia.

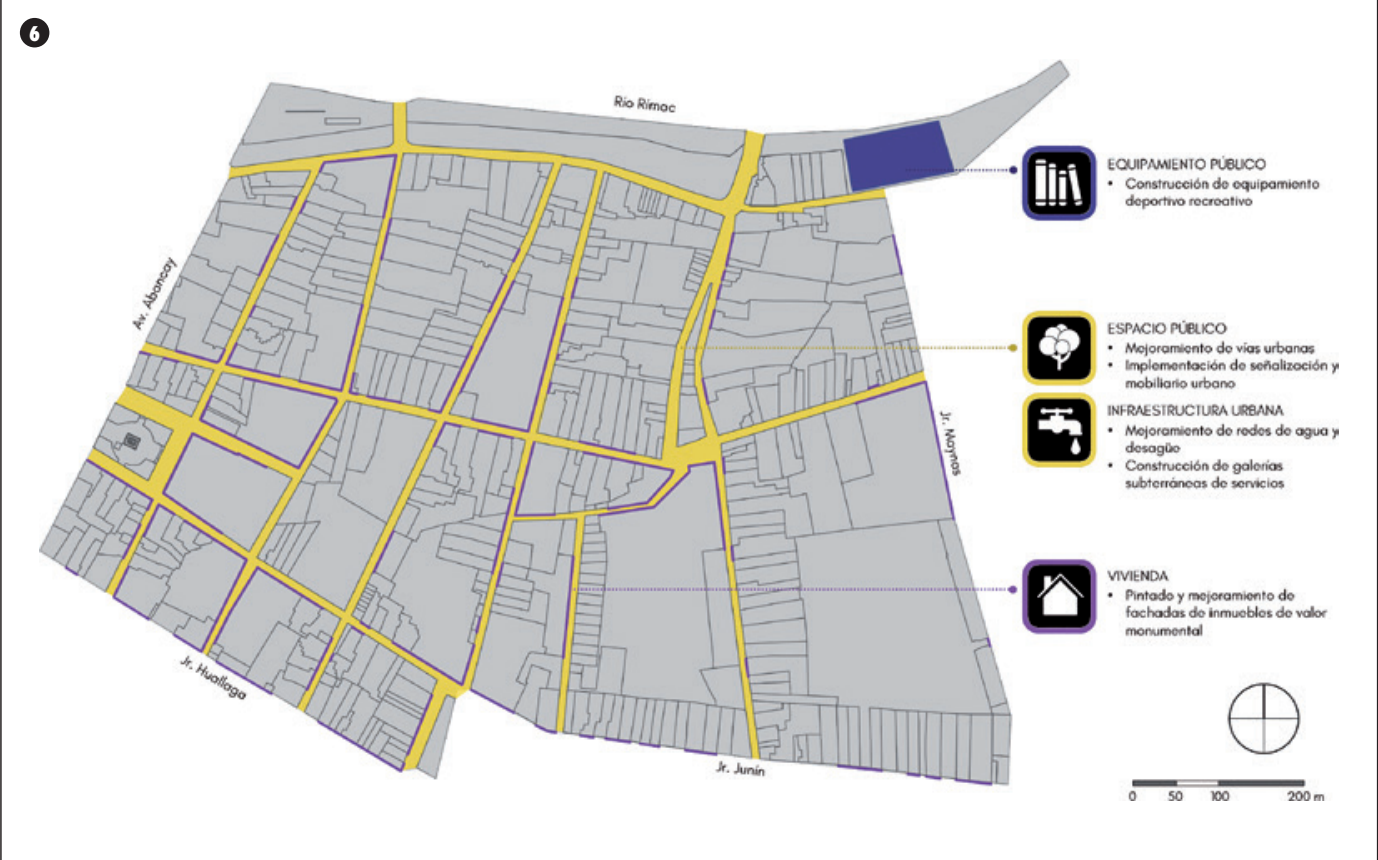

\section{LOS NIVELES DE PARTICIPACIÓN DE LA POBLACIÓN EN EL PROGRAMA DE RECUPERACIÓN DE BARRIOS ALTOS}

Para analizar la participación de la población en el programa se ha considerado: la oportunidad con que se dio el proceso participativo, quiénes participaron (los actores), cómo participaron (el proceso) y los niveles de participación alcanzados.

El programa inició su fase de diseño sin participación de la población y bajo la responsabilidad de un equipo técnico que identificó desde EMILIMA a los siguientes actores:

- Actores de la propia municipalidad. EMILIMA, Programa Municipal para la Recuperación del Centro Histórico de Lima, Sociedad de Beneficencia de Lima y las distintas gerencias de la Municipalidad Metropolitana de Lima.

- Actores externos a la municipalidad. BID, empresas de telefonía, agua y luz, ministerios de Cultura, Educación, Vivienda.
- Actores de la sociedad civil. Vecinos, adultos mayores, jóvenes y niños, comerciantes, visitantes).

El programa avanzó en su diseño técnico, sin embargo, para poder evaluar la viabilidad social del proyecto, se demandaba alguna forma de consulta. Por ello se decidió iniciar un diagnóstico social con una modalidad participativa.

El nuevo diagnóstico identificó una diversidad de grupos de interés, no reconocidos en fase inicial. (Salcedo, 2014):

- La organización formal sectorial, representada en el Presupuesto Participativo local.

- Las juntas vecinales, algunas formalizadas y otras informales, quienes cumplen el papel de enfrentar los problemas cotidianos del barrio.

- La Mesa de Concertación de Lucha contra la Pobreza, entidad que convoca y articula a organizaciones públicas y privadas vinculadas con los temas del desarrollo y que goza del respeto en la zona, por la representatividad que tiene de diversos sectores de Barrios Altos.

Normalmente se cree que obviando el reconocimiento de actores se allanan los procesos, sin darse cuenta que con ello se generan potenciales conflictos.

Los procesos de participación empleados en el diagnóstico contemplaron la consulta a jefes de hogar y a adolescentes en etapa escolar (a través de encuestas) y la realización de talleres con diferentes sectores de vecinos (comerciantes, adultos mayores, mujeres y ióvenes) para recoger sus percepciones acerca de los proyectos planteados por el programa.

El proceso de consulta fue precedido de jornadas informativas, sin embargo, se evidenciaron dos debilidades: dificultad del equipo técnico para comunicar adecuadamente las ideas a determinados sectores de la población y dificultad de la población para comprender la propuesta en su verdadero contexto. Ello mostró la necesidad de fortalecer las capacidades técnicas del equipo de ingenieros y arquitectos para comunicar sus ideas, y una mayor información de la población para comprender la propuesta.

Para lograr una ciudad inclusiva y participativa se necesita que los procesos de renovación urbana no se desliguen de acciones paralelas de fortalecimiento de capacidades de la población (Estremadoyro et al., 2010).

La población consultada, recibió con aceptación las propuestas ofrecidas desde el programa, pero al momento de expresar sus prioridades, resaltó otros problemas no identificados por la propuesta inicial (Salcedo, 2014):

- Con respecto a las redes públicas de servicios a implementarse, muchos señalaron que existían más problemas dentro de las redes internas de las viviendas, que en las redes públicas. 
7. Diagrama que ilustra las intervenciones del programa como fin y la participación como medio. Enfoque participativo de renovación urbana de Programa de Recuperación de Barrios Altos, elaboración propia.

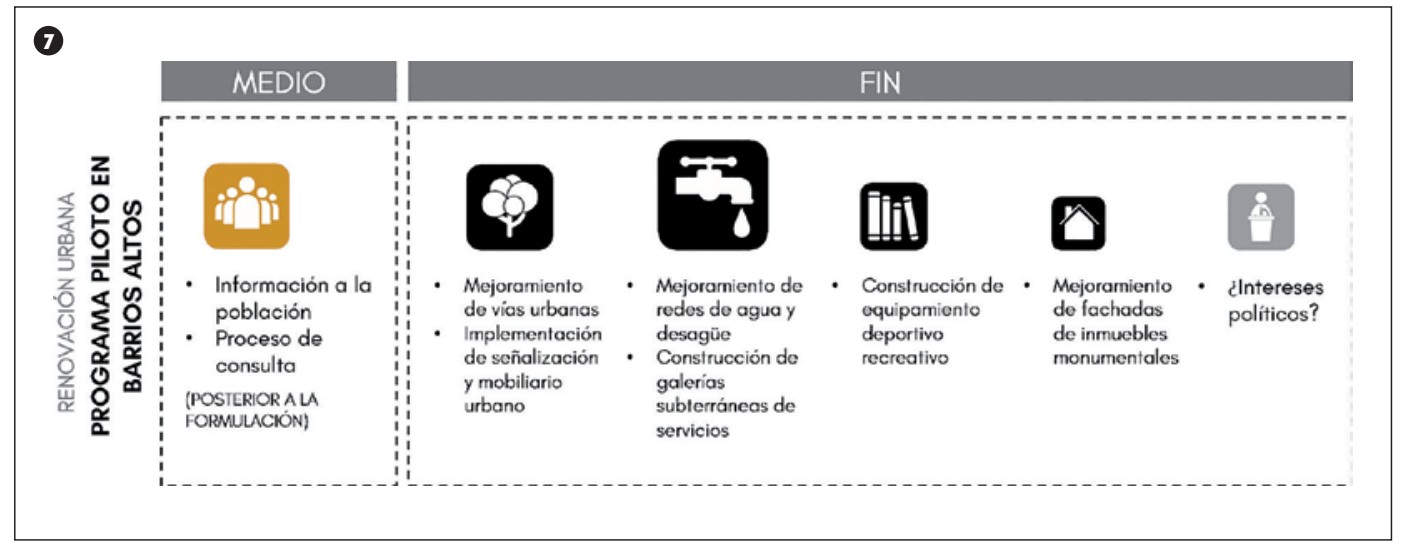

- Expresaron preocupación en relación al precio que tendrían que pagar por las nuevas instalaciones de servicios de agua y desagüe ${ }^{[7]}$, dada la situación de informalidad y la existencia de conexiones clandestinas.

- El equipamiento público deportivo planteado no consideraba la existencia de conflictos existentes e intereses alrededor del espacio (cancha de fútbol) donde se construiría.

Los niveles de participación alcanzados durante el proceso de formulación estuvieron en directa relación al enfoque instrumental de la participación evidenciado desde un inicio por el programa, donde la participación funcional era entendida como medio para lograr la aceptación y legitimación de una política de renovación urbana previamente concebida y obtener la viabilidad social, y no como fin en sí mismo (derecho de la población).

Según Fernández (2011), los ciudadanos demandan fortalecer sus capacidades y sus oportunidades de ejercer ciudadanía, dentro de espacios promovidos por el Estado. Sin embargo, en ningún momento el programa participativos, como las juntas vecinales o la Mesa de Concertación, desde la idea de derecho a la vivienda y al espacio público de los actores involucrados.

Subyace a esta postura, el no considerar la siendo esta una demanda clara y prioritaria en la población de Barrios Altos, así como asumir que la finalidad principal del proceso es la infraestructura y no las personas (FIGURA 7).

\section{HACIA UN ENFOQUE PARTICIPATIVO DE LA RENOVACIÓN URBANA}

Habiendo recogido los conceptos de participación y el análisis de la experiencia del Programa de Recuperación de Barrios Altos, es posible llegar a una síntesis conceptual de lo que significa hacer renovación urbana desde un enfoque participativo (FIGURA 8).

En esta síntesis distinguimos tres enfoques de renovación urbana, participacionista, con participación funcional y con participación comunitaria. apostó a promover o fortalecer espacios vivienda como un eje articulador del programa,

[7] Los gobiernos tienden a percibir a los hombres y mujeres como beneficiarios de los proyectos y las obras, $\sin$ informarles sobre sus derechos y deberes, ni hacerlos partícipes de la toma de decisiones sobre los servicios de agua y saneamiento. Además es importante la discusión sobre las tarifas que la población debe pagar por un servicio de agua (Zeballos y Pastor, 2007).

En la renovación urbana participacionista la participación de los ciudadanos es asumida como un instrumento al servicio de intereses particulares, sean económicos o políticos. Dichas intervenciones no suponen cambios estructurales en la configuración de la ciudad. Se ponen como ejemplo las remodelaciones de plazas y la implementación de equipamientos secundarios como los deportivos y recreativos. Los niveles de participación se limitan a la incorporación de la población en la ejecución de las obras, como mano de obra, por ejemplo.

El segundo enfoque, de renovación urbana con participación funcional, responde a las definiciones contemporáneas de renovación urbana revisadas, en las cuales la participación de la ciudadanía es un componente clave mediante el cual se logran las transformaciones urbanas. Sin embargo, la acción ciudadana se mantiene como medio con el fin de implementar los distintos procesos que incluyen los componentes de espacio y equipamiento público.

Las intervenciones tienen un nivel de restructuración de mayor impacto. Es así que se incluye la creación de nuevos espacios públicos y equipamientos de mayor relevancia para la calidad de vida de las personas, como son los de salud, educativos, culturales, etc. Los niveles de participación incluyen información a la población, procesos de consulta, recojo de propuestas de los ciudadanos y procesos de concertación y deliberación en conjunto con los representantes de la sociedad civil.

Finalmente, la renovación urbana con participación comunitaria, busca incorporar la participación como medio y como fin de los procesos de desarrollo, rescatando la idea de que toda transformación de la ciudad debería tener como último objetivo el fortalecimiento de las capacidades de la población para participar en democracia y en libertad de la vida en comunidad, haciendo ejercicio de sus derechos. Se busca entonces una ciudad inclusiva, que según Balbo (2003), es aquella 
8. Diagrama que propone tres niveles de participación en renovación urbana de acuerdo a su medio y su fin Enfoques participativos de Renovación Urbana, elaboración propia.

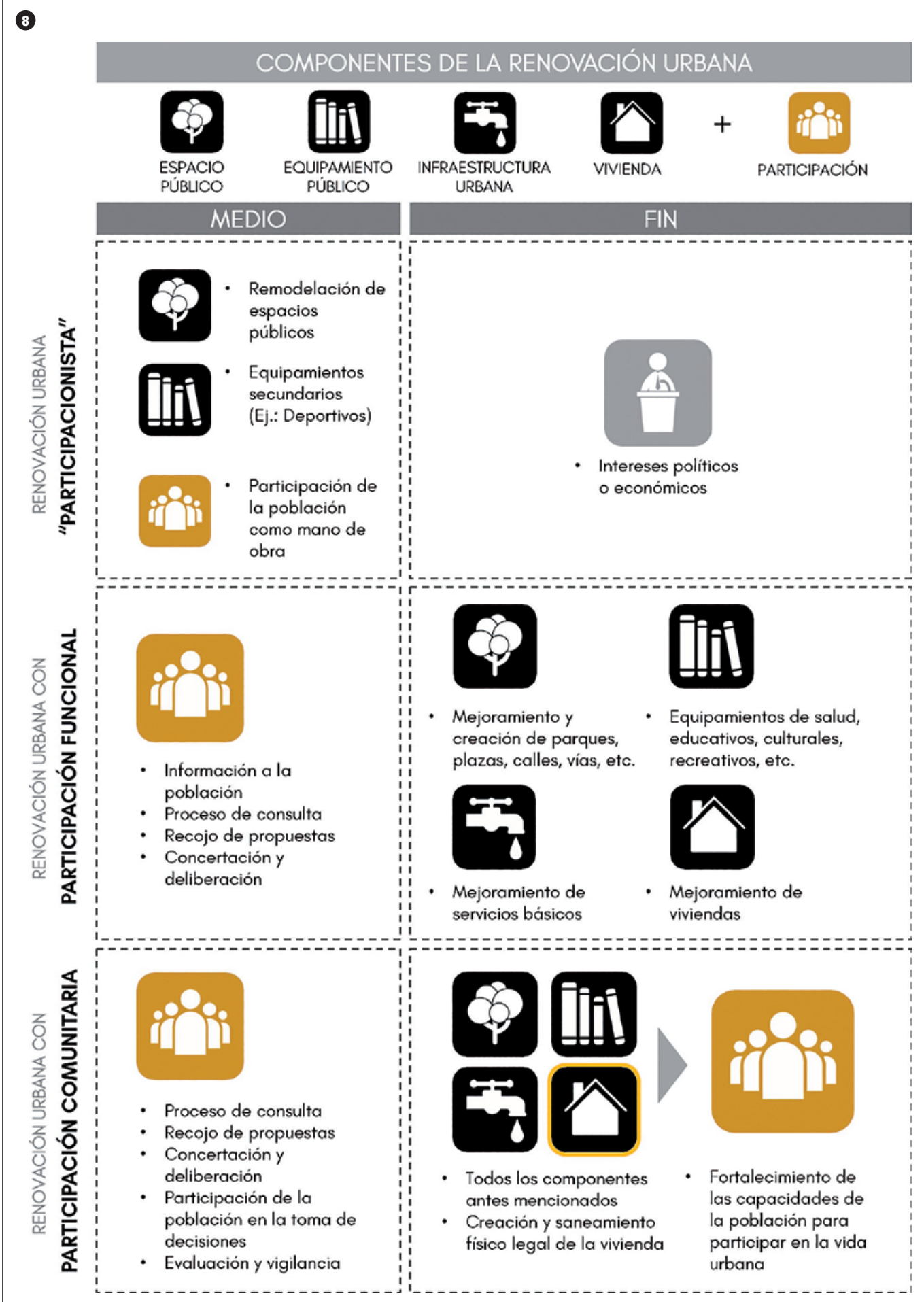

donde cualquiera, independientemente de su condición, participa de manera productiva de las oportunidades que una ciudad ofrece.

El medio por el cual se ejercen mecanismos participativos adquiere mayor nivel de envergadura, incorporando procesos de participación plena de la población en la toma de decisiones y en el seguimiento vigilante a las políticas e intervenciones ya ejecutadas.

Los componentes de renovación urbana engloban todos los antes mencionados en los enfoques previos. Sin embargo, se hace especial énfasis en el componente de vivienda, que implica la solución a problemáticas de mayor complejidad (saneamiento físico legal, vulnerabilidad física, déficit de vivienda, tugurización, salubridad, etc.) y que requiere un nivel de involucramiento mayor de la población. En la renovación urbana, la vivienda es el eje articulador entre la población y la ciudad (Estremadoyro et al., 2010).

\section{CONCLUSIONES}

El caso analizado en la zona de Barrios Altos pone en evidencia algunas características de la intervención de renovación urbana, relevantes para una reflexión acerca de la participación ciudadana en tales proyectos.

La experiencia del Programa de Recuperación de Barrios Altos denota que existe un tratamiento de algunos problemas de la ciudad desde un enfoque fragmentado, que no incluye en su concepción inicial, al ciudadano y sus necesidades como fin último de la intervención.

La oportunidad con que se convoca la participación es decisiva para el diseño de un proyecto. El caso revisado mostró que el diagnóstico social participativo permitió identificar, actores e intereses no reconocidos inicialmente por el equipo técnico, nuevas necesidades y percepciones importantes para las decisiones de diseño del programa. Su 
realización oportuna, hubiese minimizado riesgos e involucrado a los interesados.

El caso muestra con claridad que en el escenario inicial de diseño del proyecto la población no es considerada como sujeto de consulta. Su incorporación se decide con el objetivo de cumplir con un requisito de viabilidad, y no como finalidad (ejercicio de su derecho).

El caso mostró dificultades en el proceso de consulta realizado, tanto en la capacidad de comunicación del equipo técnico como en la comprensión lograda por los actores.

Desde una perspectiva más general de la renovación urbana, es importante que la arquitectura pueda asumir un paradigma claro de renovación urbana participativa, a fin de superar los modelos tradicionales de actuación pública, que minimizan la participación de las personas, reduciéndose a un rol instrumental. Para poder lograr este fin, no solo hace falta una legislación clara que exija el desarrollo de procesos participativos, sino el desarrollo de las capacidades en las instituciones públicas para llevarlos a cabo de manera satisfactoria.

Las intervenciones físicas deben ser acompañadas de estrategias claras de identificación de los actores, metodologías que garanticen la participación, incluyendo el desarrollo de capacidades que permitan que las edificaciones, infraestructuras y espacios proyectados puedan ser de apropiación de los ciudadanos. También la población debe ser empoderada con el conocimiento de sus derechos, concientizada con el sentido del deber e informada o capacitada para poder comprender y acompañar este proceso desde su concepción hasta su implementación.

Como se ha visto, la participación en la renovación urbana distingue diversos alcances. El artículo propone un enfoque de participación comunitaria, donde las personas no solo sean medios sino fines de la renovación, lo cual además garantiza legitimidad y sostenibilidad de los procesos de transformación de la ciudad.

El enfoque de participación comunitaria no solo debe ser aplicado a la escala de proyectos de renovación urbana, sino que debe constituirse en un factor a tener en cuenta en todo nivel de proyecto arquitectónico. El edificio, la plaza, el espacio, no son el fin último de la labor de un arquitecto, sino un medio potente para lograr que el ser humano sea partícipe de una vida en pleno uso de sus capacidades y libertades.

\section{REFERENCIAS BIBLIOGRÁFICAS}

Agencia Española de Cooperación Internacional para el Desarrollo, AECID, (ed.) (2011). Catálogo del concurso 5 ideas para el Centro Histórico de Lima. Recuperado de https://issuu.com/ jorgeluischavez/docs/catalogo_concursochlima/1 ?e $=3332377 / 2637540$

Agencia Española de Cooperación Internacional para el Desarrollo, AECID, (ed.) (2012). Catálogo del concurso Tratamiento integral de 5 Espacios Públicos en el Jr. Ancash. Recuperado de http://issuu.com/jorgeluischavez/ docs $/ 5$ espaciospublicos $/ 1 ? \mathrm{e}=0$

Alegre, M. (coord.) (2014). Estudio socioeconómico para conocer la capacidad y disposición de pago de los hogares de Barrios Altos, Centro Histórico de Lima, con fines de renovación urbana. Lima: Eficiencia legal para la Inclusión Social.

Balbo, M. (2009). La ciudad inclusiva. Cuadernos de la CEPAL, (88), 305-313. Recuperado de http://repositorio.cepal.org/bitstream/ handle/11362/27814/1/S2003002_es.pdf

Bronfman, M. y Gleizer, M. (1994). Participación comunitaria: ¿̇Necesidad, excusa o estrategia? $O$ de qué hablamos cuando hablamos de participación comunitaria. Cadernos de Saúde Pública, 10 (1), 111-122.

Recuperado de http://www.scielo.br/pdf/csp/ v10n1/v10nla12

Caicedo, V. E. (2013). Modelo urbano participativo. El caso del Plan Parcial Fenicia en Bogotá. Cuadernos de Vivienda y Urbanismo, 6 (12).
Recuperado de http://revistas.javeriana.edu.co/ index.php/cvyu/article/download/5344/4545

Cañizares, B. Z. (marzo, 2013). Actores sociales: claves analíticas para una aproximación problematizadora. Centro de Estudios Interdisciplinarios en Problemáticas Internacionales y Locales. Recuperado de http:// www.ceipil.org.ar/wp-content/uploads/2013/03/ Ca\%C3\%B 1 izares-Brian.pdf

de la Cruz, L. (mayo, 2016). El participacionismo como tapón democrático. Blog Improvistos. Recuperado de http://www.improvistos.org/es/elparticipacionismo-como-tapon-democratico

Empresa Municipal Metropolitana de Lima, EMILIMA, (2014). Programa Piloto de Recuperación del Centro Histórico de Lima-Barrios Altos.

Espejo, R. (2009). Desarrollo humano y participación comunitaria. Algunas reflexiones desde el enfoque gestáltico de Paul Goodman. Polis. Revista Latinoamericana, (23). Recuperado de http:// polis.revues.org/1767

Estremadoyro, L., Uceda, C., Obregón, A. y O’Phelan, C. (2010). CEPROMUR y los procesos de renovación urbana. Lima: CEPROMUR.

Fernández, V. (2011). Participación ciudadana reactiva: el caso del Plan Regulador de la comuna de Peñalolén y la modificación del Parque Los Domínicos en la comuna de Las Condes. Revista de Arquitectura, 17(24), 26-33, http://dx.doi.org/10.5354/07195427.2011.26910

Guillen, A., Sáenz, K., Badii, M. H. y Castillo, J. (2009). Origen, espacio y niveles de participación ciudadana. Daena: International Journal of Good Conscience, 4(1), 179-193. Recuperado de http://www.spentamexico.org/v4-n 1/4(1)\%20 179-193.pdf

Hamann, J (2011). El nacimiento de Lima: La imposición de un nuevo orden. On the Waterfront, (19). Recuperado de http:// raco.cat/index.php/Waterfront/article/ download/249795/334188

Hernandez, F. (2013). Abordaje teórico de la renovación urbana como proceso de transformación de la estructura urbana. Aplicación en el casco histórico de la ciudad de Mendoza, Argentina. Revista del Departamento de Geografía, 2(2), 49-69. Recuperado de 
https://revistas.unc.edu.ar/index.php/cardi/ article/view/7381

Lira, J. (abril, 2016). Editorial. Urbanismo: otra gran ausencia. Diario Gestión. Recuperado de http://gestion.pe/opinion/urbanismo-otra-granausencia-2158584

Maffrand, G. y Martínez Rusconi, M. (2001). La gestión participativa en la construcción del hábitat residencial. Experiencia con 54 familias dispersas de Villa Libertador. Revista Invi, 16(43). Recuperado de http://revistainvi.uchile.cl/index. php/INVI/article/view/410/801

Municipalidad Metropolitana de Lima (2014). Plan Específico de Barrios Altos (Cercado de Lima y El Agustino) 2014-2025. Resumen Ejecutivo. Recuperado de http://www.munlima.gob. pe/images/descargas/gerencias/GDU/PlanEspecifico-Barrios-Altos-Resumen-Ejecutivo.pdf

Palma, D. (2000). La participación y la construcción de ciudadanía. Investigación y Crítica, (4), 22. Recuperado de http://www. plataformademocratica.org/Publicacoes/4744. pdf

Salcedo, E. (2014). Informe de Diagnóstico Social para el Programa Recuperemos Barrios Altos. Empresa Municipal Inmobiliaria de Lima.
Sandoval, P. (febrero, 2016). Construyen 30 mil casas informales al año en Lima. Diario El Comercio. Recuperado de http://elcomercio.pe/sociedad/ lima/construyen-30-mil-casas-informales-al-anolima-noticia-1880895

Shimabukuro, A. (2015). Barrios Altos: Caracterización de un conjunto de barrios tradicionales en el marco del Centro Histórico de Lima. Revista de Arquitectura, 17(1), 6-17. Recuperado de http:// www.redalyc.org/pdf/1251/125143817002.pdf

Universidad de Buenos Aires, UBA, (2013). Actores Sociales. Cursos Online. Facultad de Arquitectura, Diseño y Urbanismo. Recuperado de http://cursos.fadu.uba.ar/cursos/004/ Actoressociales_doc

Vargas, A. (coord.) (2014). Consultoría: Elaboración de análisis, diagnóstico y propuesta legal, técnica y financiera con fines de renovación urbana en una zona de Barrios Altos. Lima: Banco Interamericano de Desarrollo.

Vergara Constela, C. (2013). Gentrificación y renovación urbana. Abordajes conceptuales y expresiones en América Latina. Anales de Geografía, 33(1), 219-234. Recuperado de http://revistas.ucm.es/index.php/AGUC/article/ viewFile/43006/40809
Vidal Gómez, B. (2014). Diseño de barrio mediante estrategias participativas. Vivienda de interés social en Los Guido de Desamparados, Costa Rica. En Máster Laboratorio de la Vivienda Sostenible del Siglo XXI (436-441). Recuperado de http://hdl.handle.net/2099/15391

Vives, L. E. (2013). Análisis de la renovación urbana como estrategia de recuperación del Centro Histórico de Santa Marta. Estudio de caso: Plan Especial de Protección del Centro Histórico del Distrito Turístico, Cultural e Histórico de Santa Marta. Periodo 2000-2011. (Tesis de pregrado, Universidad Colegio Mayor de Nuestra Señora del Rosario, Bogotá, Colombia). Recuperado de http://repository.urosario.edu.co/ handle/10336/4749

Zeballos, M. \& Pastor, R. (2007). Agua, género y ciudadanía. Incluyendo a hombres y mujeres en la gestión de los servicios de agua y saneamiento. Lima: Ministerio de Vivienda, Construcción y Saneamiento. Recuperado de https://www.wsp.org/sites/wsp.org/files/ publications/1 16200730024 _DiagGENesp.pdf 